\title{
Design of Multiband Microstrip Antenna for Mobile Wireless Communication
}

\author{
OGUNLADE Michael Adegoke, ZHENG Hong-xing* \\ Institute of Antenna and Microwave Techniques \\ Tianjin University of Technology and Education, Tianjin 300222, China \\ *Email: hxzheng@126.com
}

\section{Keywords: Multiband Antenna; Compact Size; Microstrip Structure}

\begin{abstract}
A multiband rectangular microstrip antenna is designed and fed by microstrip line, which consists of three radiating elements operating in three frequencies at $2.4 \mathrm{GHz}, 3.6 \mathrm{GHz}$ and $5.6 \mathrm{GHz}$. This antenna is implemented on FR4-Epoxy dielectric substrate with relative permittivity of 3.38, substrate thickness of $1.52 \mathrm{~mm}$ and dielectric loss tangent of 0.0027 . The return loss and voltage standing wave ratio are less than $-10 \mathrm{~dB}$ and 2 respectively. Its compact size is with operation in wireless local area network and worldwide interoperability for microwave access communication.
\end{abstract}

\section{Introduction}

There are different shapes of antenna depending on its application. In general, the microstrip antenna has many unique and attractive properties. There seems to be little doubt that it will continue to find many applications. These properties include low profile, light weight, being compact and conformable to mounting structure, easy fabrication and integration with solid-state devices. These properties contribute to the successful application of microstrip antennas not only in the military, such as aircraft, missiles, space craft, but also in the commercial areas, such as mobile satellite system, terrestrial cellular communications, broadcast satellite system, and global positioning system. Recently, technology advances have improved its bandwidth from a few percent to tens of percent [1]. There are numerous and well-known methods to increase the bandwidth of antennas, including increase of the substrate thickness, the use of a low dielectric substrate, and the use of multiple resonators [2],[3].Therefore, the interest in multiband antenna is increasing, especially in order to reduce the number of antenna embedded in combining multiple application on a single antenna[4].

In this paper, researchers propose an antenna designed with FR4-Epoxy dielectric substrate, which has the width and length of $\mathrm{W}=35 \mathrm{~mm}$ and $\mathrm{L}=34 \mathrm{~mm}$ respectively. Moreover, the design has been simulated by using high frequency structure simulator software (HFSS) [5]. The operating bands are evaluated by using the software with the criterion of return loss S11 less than $-10 \mathrm{~dB}$. With reference to the simulation results, it is shown that the multiband antenna has achieved good results once researchers make comparison with the IEEE 802.11/N [6] for verification.

\section{Size, Structure and Design Equations}

In the present study, researchers are interested in the rectangular shape multiband antenna, which is widely used in cell phones, WiMAX [7] and mobile communication. There are various shapes of microstrip antennas. A rectangular patch shape is used for efficient and good performance of this antenna. Also, a thick substrate having a low dielectric constant is used, providing better efficiency, relatively improved bandwidth and better radiation pattern. However, this configuration increases the size of the antenna. One of the major factors that were put into consideration was that a substrate with good dielectric constant is used. The dielectric constant is properly chosen such that it gives better efficiency and larger bandwidth. The effective dielectric constant is a function of frequency. As the operation frequency increases, the effective dielectric constant approaches the value of dielectric constant of the substrate [8]. A substrate with high dielectric constant reduces the 
dimensions of the antenna but it also affects antenna performance. Hence, the height of the dielectric substrate should be less than 3. All these factors are put into consideration. The proposed structure is shown in Fig. 1.

In order to make this antenna meet the design requirements, researchers follow some procedures as follows: First of all, researchers have chosen the dielectric permittivity of the dielectric to give maximum bandwidth, and chosen the dielectric from FR4-Epoxy dielectric constant $\varepsilon r=3.38$, Substrate $\mathrm{h}=1.52 \mathrm{~mm}$ and dielectric loss tangent $\delta=0.0027$. As for the substrate selection, the major consideration is the dielectric constant. A high dielectric constant will result in a smaller patch size but this will generally reduce bandwidth efficiency and might have difficulty in fabricating a very small patch size antenna [9]. The two most popular and often used closed-form equations for the fundamental-mode rectangular patch are given by:

$$
F=\frac{C}{\left(2[L+h] \sqrt{\epsilon_{\varepsilon}}\right)}
$$

Where, $\mathrm{F}=$ Resonant Frequency; $\mathrm{C}=$ Speed of Light $(3 \times 108 \mathrm{~m} / \mathrm{s}) ; \in_{\Gamma}=$ Relative dielectric Constant; $\epsilon_{\varepsilon}=$ Effective dielectric Constant; $\mathrm{h}=$ Thickness of the substrate; $\mathrm{L}=$ Length of the patch; $\mathrm{W}=$ Width of the microstrip Patch antenna. L0, L1, L2, R1, R2, R3, R4 are the Patch resonant Length. Hence, the effective dielectric constant is given as:

$$
\epsilon_{\varepsilon}=\left(\frac{\epsilon_{\Gamma}+1}{2}+\frac{\epsilon_{\Gamma}-1}{2}\right) / \sqrt{\left(1+\frac{12 h}{W}\right)}
$$

These equations are used in predicting the resonant frequency, substrate thickness and dielectric constant of the antenna.

The above concept is followed. Researchers have tried to use the size given in the Table 1 and then investigated their availability.

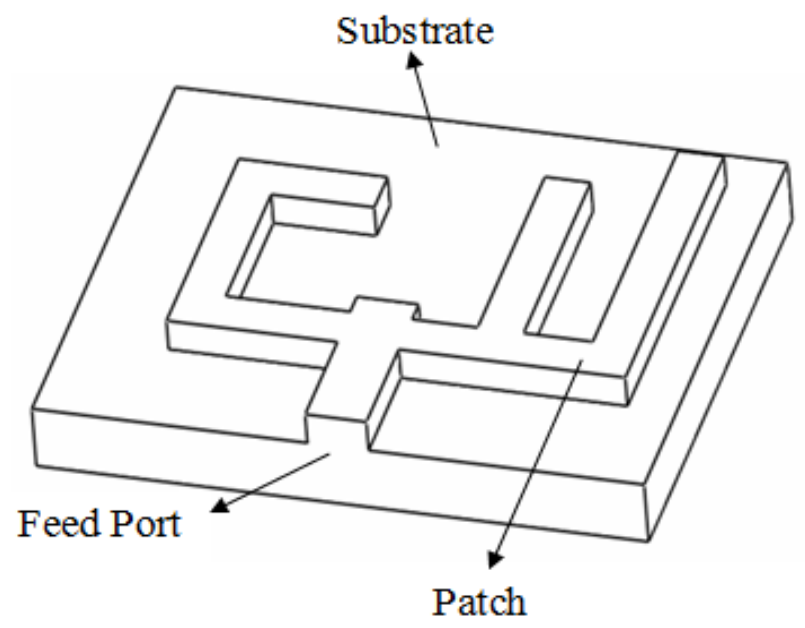

Fig. 1 Antenna Geometry

Table 1 Design Parameters of the Proposed Antenna (Unit: mm)

\begin{tabular}{cccccccccc}
\hline $\mathrm{H}$ & $\mathrm{S}$ & $\mathrm{L} 0$ & $\mathrm{~W}$ & $\mathrm{~L} 1$ & $\mathrm{~L} 2$ & $\mathrm{R} 1$ & $\mathrm{R} 2$ & $\mathrm{R} 3$ & $\mathrm{R} 4$ \\
\hline 1.52 & 2.00 & 13.20 & 1.80 & 3.70 & 8.90 & 10.00 & 2.10 & 15.20 & 22.00 \\
\hline
\end{tabular}

\section{Feeding Technique}

Microstrip Patch antenna can be fed by a variety of methods. However, the methods can be classified into contacting and non-contacting methods. In the case of contacting method, the RF power is fed 
directly to the radiating patch by using a connecting element like microstrip line. Similarly, in case of the non- contacting method, the electromagnetic field coupling is done to transfer power between the microstrip line and the radiating patch [10]. There are four types of feed techniques, including microstrip Line, coaxial probe, aparture coupling, and proximity coupling [11]-[14]. For this design, microstrip line method is used. In this type of feed techniques, a conducting strip is smaller in width as compared to the patch, and this kind of feed arrangement has the advantage that the feed can be etched on the same substrate to provide the shape. The purpose of the inset cut in the patch is to match the impedance of the feed line to the patch without the need for any additional matching element. This is achieved by properly controlling the inset position. Hence this is an easy feeding scheme, since it provides easy fabrication and simple modeling as well as impedance matching. However, as the thickness of the dielectric substrate being used increases, surface waves and spurious feed radiation also increases, which hampers the band-width of the antenna. This method has advantages over the other methods due to its simple structure.

\section{Simulation Result}

Parametric analysis is done in order to show the effects of different parameters on frequency. The parameters are changed in length and width of the patch and the substrate. The effects on frequency with respect to the above mentioned parameters are noted. The first designed and analyzed parameter is the length of the patch of the antenna. These parameters are denoted as: L1, L2, R1, R2, R3, R4 and $\mathrm{W}$, and $W$ respectively. It is observed that if the patch length is increased, the resonant frequency starts to decreased; if the patch length is decreased, the frequency starts to increase. It is clear that there is a regular pattern in change of resonant frequencies with change in the patch length. After optimizing the patch length along with other parameters, the required operating frequency is achieved at $2.4 \mathrm{GHz}, 3.6 \mathrm{GHz}$, and $5.6 \mathrm{GHz}$ respectively. In addition, it is observed that with the increase in the width of patch, the resonant frequency of the antenna also increases; with the change of resonance frequency at a regular trend, the patch width also changes. However, the current distribution is changed by changing the length of ground plane. The suggested antenna design requires a small space. When being connected to a $50 \mathrm{ohms}$ source, a VSWR $<2$ across the $2.4 \mathrm{GHz}$, $3.6 \mathrm{GHz}$, and $5.6 \mathrm{GHz}$ ISM band should be provided. The radiation pattern values at each frequency are shown in Fig. 2. The reflection at the feed point of the antenna determines how much the applied power is delivered to the antenna. Reflection of less than $-10 \mathrm{~dB}$ is obtained, implying that $90 \%$ of the available power is delivered to the antenna. The bandwidth is the frequency range, and the performance of antenna satisfies the specified standards of antenna parameters. From the design, at $2.4 \mathrm{GHz}$, the upper frequency band is $2.40 \mathrm{GHz}$ and the lower frequency band is $2.30 \mathrm{GHz}$ with a return loss of 14.0083 respectively. The bandwidth is the difference between the upper frequency and the lower frequency. The simulation results for the return loss, VSWR and bandwidth is shown in Table 2.

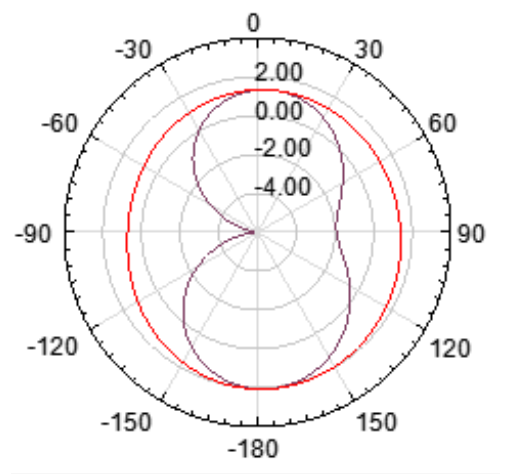

(a)

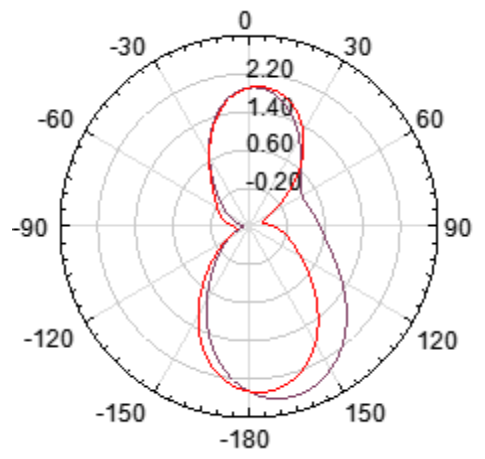

(b)

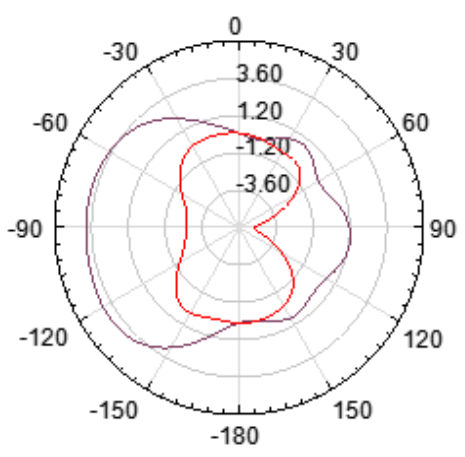

(c)

Fig. 2 Radiation Pattern at (a) $2.4 \mathrm{GHz}$, (b) $3.6 \mathrm{GHz}$, (c) $5.6 \mathrm{GHz}$ 
Table 2 Simulation Results at $2.4 \mathrm{GHz}, 3.6 \mathrm{GHz}, 5.6 \mathrm{GHz}$

\begin{tabular}{cccc}
\hline Freq. $(\mathrm{GHz})$ & $\mathrm{S} 11(\mathrm{~dB})$ & VSWR & BW $(\mathrm{MHz})$ \\
\hline 2.4 & -14.01 & 1.49 & 130 \\
3.6 & -13.78 & 1.51 & 200 \\
5.6 & -18.32 & 1.31 & 600 \\
\hline
\end{tabular}

\section{Application}

Antenna is a vital component of any communication system, which is used at both the transmitting end and the receiving end. It is a conduction device being made up of conductor. At the transmitting end, it converts the electrical energy into the space. At the receiving end, it receives the electromagnetic waves and transforms them into electrical signal which acts an input to the receiver. The popular applications of this antenna includes; Wi-Fi, WiMAX, Bluetooth and WLAN's. These are standard that allows devices to communicate with each other by using a Wi-Fi router as the central hub. All devices with Wi-Fi connected to router can have data exchanges between them or even with other devices on the internet, provided the router has an internet access or any of the devices. The single band $\mathrm{Wi}-\mathrm{Fi}$ router operates at $2.4 \mathrm{GHz}$ frequency and the dual band router supports both $2.4 \mathrm{GHz}$ and $5.4 \mathrm{GHz}$ only at a time. If there are users using both $2.4 \mathrm{GHz}$ and $5 \mathrm{GHz}$ you need to set up two routers with one operating at $5 \mathrm{GHz}$ and other at $2.4 \mathrm{GHz}$.

Another application is Worldwide Interoperability for microwave Access (WiMAX). This has been widely applied in mobile devices, such as handheld computers and intelligent phones, and this gives user the mobility to move around within a broad coverage area and still be connected to the network. This provides greatly increased freedom and flexibility. For the home users, wireless has become popular due to easy installation and location freedom. Therefore, there is continuously increased requirement of efficient and high performance antenna. This technique has been widely recognized as a viable, cost-effective and high-speed data connectivity solution, enabling user mobility. In practice, IEEE 802.11 WiMAX Standards consist of $3.6 \mathrm{GHZ}$, and $5.5 \mathrm{GHz}$ frequency bands.

\section{Conclusion}

The analysis and design of microstrip antenna for wireless communication is presented. The proposed antenna can cover WI-Fi, WiMAX, and WLAN frequency band with values of VSWR at all these resonating frequencies $<2$ and $>1$, ensures that more than $90 \%$ of the available power is delivered to the antenna. Therefore, researchers can say that the designed antenna is resonating at three different frequencies. All these frequencies have their own operations. The proposed antenna is very compact, very easy to fabricate, hence can be manufactured in large quantities. It is fed by a $50 \Omega$ microstrip line, making it very attractive for current and future cellular phones. The major parameters considered for the antenna design are the radiation pattern, the voltage standing wave ratio, return loss and the operating frequency. The bandwidth is the range of frequencies on either side of the center frequency, where the antenna characteristics like input impedance, radiation pattern, beam width etc are close to those values, which have been obtained at the central frequency. The 
bandwidth is the ratio of upper frequency and the lower frequency known as broadband. Often, the desired bandwidth is one of the major determining parameters used to decide upon an antenna. For instance, many antenna types have narrow bandwidths and cannot be used for wide band opearation. Bandwidth is typically quoted in terms of Voltage Standing Wave ratio. It is often specified in terms of its fractional Bandwidth. The voltage standing wave ratio defines how far the impedance differs from $50 \mathrm{ohms}$ with a wide-band antenna. In addition, the return loss S11 represents how much power is reflected from the antenna. If $\mathrm{S} 11=0 \mathrm{~dB}$ then, all the power is reflected from the antenna and nothing is radiated. But, if $S 11=-10 \mathrm{~dB}$ the standard value, this implies that if $3 \mathrm{~dB}$ of power is delivered to the antenna, $-7 \mathrm{~dB}$ is the reflected power. The rest was accepted by the antenna. This accepted power is either radiated or absorbed as losses within an antenna. Since antennas are typically designed to be low loss, the majority of the power deliverd to the antenna is radiated. The return loss is the difference between forward and reflected power in $\mathrm{dB}$.

\section{Acknowledgments}

This work was supported by the National Nature Science Foundation of China, the Natural Science Foundation of Tianjin Municipality and Advanced Technology, China, and the Science Research and Development Foundation of Tianjin University of Technology and Education, China, Grant 61371043, 12JCYBJC10500, and KJY14-04, respectively.

\section{References}

[1] C. A. Balanis, Antenna Theory-Analysis and Design, Second Edition, John Wiley and Sons, Inc., 1997.

[2] K. L. Lau, K. M. Luk, and K. Fong Lee, Design of a Circularly-polarized Vertical Patch Antenna, IEEE Transactions on Antennas and Propagation, 54(2004) 68-78.

[3] M. Samsuzzaman, M. T. Islam, J. S. Mandeep, Triple Band X Shape Microstrip Patch Antenna for Ku/K Band Applications, Modern Applied Science, 7(2013) 70-81.

[4] H. S. A. Abutarboush Raweshidy and R. Nilavalan, Compact Double U- slots Patch Antenna for Mobile WiMax Applications", IEEE 14th Asia-Pacific Conference on Wireless Networks \& Commun. Brunel Univ., London, 2008.

[5] K. G. Thomas and M. Screenivasan, A Novel Triple Band Printed Antenna for WLAN/WiMAX Applications, Microwave and Optical Technology Letters, 51(2009) 2481- 2485.

[6] C. A. Pittsburgh HFSS User's Guide, Version 13, Ansoft Corporation, 2005.

[7] S. K. Gupta, A. Sharma, B. K. Kanaujia, G. P. Pandey, Triple Band Circular Patch Microstrip Antenna with Superstrate Wireless Personal Communications, 77(2014) 395-410.

[8] S. Radiom, B.-N. Majid, A. Hadi, et al, Miniaturization of UWB Antennas and Its Influence on Antenna-transceiver Performance in Impulse-UWB Communication, Wireless Personal Communications, 71 (2013) 2913-2935.

[9] X. -B. Ma and H. -X. Zheng, A Compact Tri-band Bandpass filter with Adjustable Third Passband Using Square Open Loop Resonator Embedded by Open Stubs, Microwave and Optical Technology Letters, 54(2012) 1817-1819.

[10] R. Garg. P. Bahl, A. Itipibon, Microstrip Antenna, Boston-London, 2000.

[11] M. J. Ammann, Z. N. Chen, Wideband Monopole Antennas for Multi-band Wireless Systems, IEEE Antennas and Propagation Magazine, 45(2003) 146-150. 
[12] Q. Zhao, S. X. Gong, W. Jiang, B. Yang, and J. Xie, Compact Wide-slot Tri-band Antenna for WLAN/WiMAX Applications, Progress In Electromagnetic Research Letters, 18 (2010) 9-18.

[13] S. Chatterjee, U. Chakraborty, I. Sarkar, S. K Chowdhury, P. Sarkar, A Compact Microstrip Antenna for Mobile Communication, IEEE Annual Conference, 2011. Paper ID 510.

[14] J. H. Yoon, Fabrication and Measurement of Rectangular Ring with Opened CPW-feed Monopole Antenna for $2.4 / 2.5 \mathrm{GHz}$ WLAN Operation, Microwave and Optical Technology Letter, 48(2006) 1480-1483. 